\title{
THE 7TH WORLD WONDER OF IT - INTUITION-BASED ANALYTICS FOR THE DIGITAL ECONOMY \& SOCIETY
}

\author{
Andreas Meier \\ University of Fribourg \\ Boulevard de Pérolles 90, CH-1700 Fribourg, Switzerland
}

\begin{abstract}
Computer Science is a relatively young discipline. However, the impact of IT to business, economy, and society is huge. Without information systems and web-based services, our industry as well as our public live would suffer. In this overview paper, we therefore list seven world world wonders of IT and focus on the seventh, i.e. fuzzy logic and its derivatives. In fuzzy logic, the classical truth values true (1) and false (0) are extended by infinite truth values between 0 and 1 . These values open a new way of thinking, i.e. thinking in degrees of truth rather than in black and white terms. Three short case studies - fuzzy portfolio techniques, intuition-based service management, and fuzzy voting - illustrate the potential of soft computing in different application domains. Finally, we summarize the 'grand paradigm shift' of fuzzy logic for mathematics and other areas of science, but also for engineering, management, decision-making, risk analysis, and last but not least, for our knowledge-based society.
\end{abstract}

\section{KEYWORDS}

Fuzzy Logic, Intuitionistic Fuzzy Logic, Fuzzy Portfolio Technique, Intuition-Based Service Management, Fuzzy Voting, Digital Society

\section{INTRODUCTION}

In the age of big data, immense amounts of information are collected from various sources: postings from social networks, e-mails and correspondence, inquiries from search engines, document collections from content management systems, sensor data of any kind, price developments of stock exchanges, data from traffic flows, satellite images, video recordings, measurement data from household appliances (smart meters), purchasing and ordering processes from electronic shops, data from e-health applications, or recordings from electronic monitoring systems.

What about the quality and significance of these data? The original 3-V-model (Volume, Variety, Velocity), introduced by Doug Laney for a first definition of big data, was gradually supplemented by further V's: Value, Veracity, Validity, Volatility, Vulnerability, or Viability. Validity refers to the meanin gfulness, Veracity stands more for truthfulness or credibility of the data.

This makes it clear that data and the information derived from it are often misleading, indefinite, inaccurate, uncertain, or vague. It is therefore imperative to develop procedures which evaluate the gradual truth of the data. One solution is to apply the fuzzy logic of Lotfi Zadeh to process vague information.

Lotfi Zadeh laid the foundation for fuzzy logic in 1965 with his research paper 'Fuzzy Sets' (Zadeh 1965). Fuzzy sets are sets where all elements' belonging to the set are measured with a membership function $\mu$ that can take values on the unit interval $[0,1]$. Thus, one extends a classical set of elements by giving each element its measure of belonging to the set: If $X$ is the universal set, and $A$ is a subset of $X$, then the fuzzy set $A$ is defined as $\mathrm{A}=\left\{\left(\mathrm{x}, \mu_{\mathrm{A}}(\mathrm{x})\right) \mid \mathrm{x} \in \mathrm{X}, \mu_{\mathrm{A}}(\mathrm{x}): \mathrm{X} \rightarrow[0,1]\right\}$.

In 1983, the mathematician Krassimir Atanassov extended the fuzzy membership function $\mu$ with the non-membership function $v$ (Atanassov 2012, Atanassov 2016): If $X$ is the universal set, and A is a subset of $X$, an intuitionistic fuzzy set $A$ is defined as $A=\left\{\left(x, \mu_{A}(x), v_{A}(x)\right) \mid x \in X, \mu_{A}(x): X \rightarrow[0,1], v_{A}(x): X \rightarrow\right.$ $[0,1]$, where $\left.0 \leq \mu_{A}(x)+v_{A}(x) \leq 1\right\}$. 

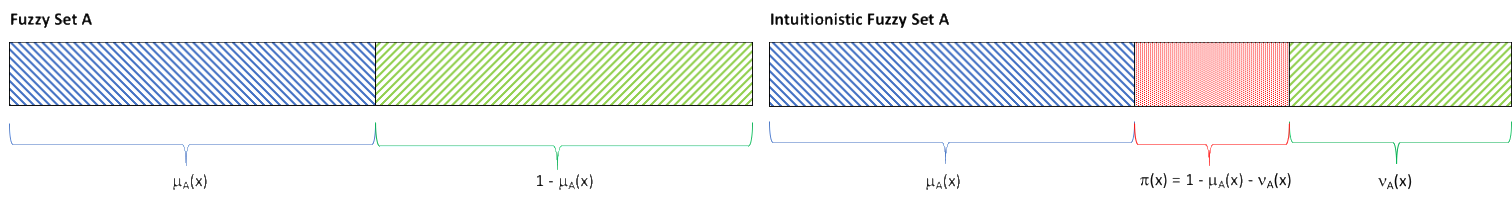

Figure 1. Comparison of Fuzzy Sets and Intuitionistic Fuzzy Sets

It is obvious that fuzzy sets are a special case of intuitionistic fuzzy sets (see Figure 1). The intuitionistic fuzzy set $\mathrm{A}$ is divided into three parts: The first part contains all elements $\mathrm{x}$, which belong to a certain degree to the set $A$, i.e., their membership values are $\mu_{\mathrm{A}}(\mathrm{x}) \geq 0$. The third part lists all elements $\mathrm{x}$, which do not belong to the set A, i.e.,, with $v_{A}(x) \geq 0$. The middle part, characterized by the function $\pi(x)=1-\mu_{A}(x)-v_{A}(x)$, expresses the degree of uncertainty or indeterminacy. For these elements, it cannot be determined whether they belong to a certain degree, to the set $\mathrm{A}$ or to $\neg \mathrm{A}$.

The objective of this overview paper is to demonstrate the potential of fuzzy logic and intuitionistic fuzzy logic. Section 2 proposes seven world wonders of IT including computing by intuition. In section 3, three case studies are given: fuzzy portfolio techniques (section 3.1), intuition-based service management (3.2), and fuzzy voting (3.3). The lessons learned and a short outlook about the 'grand paradigm shift' (Belohlavek et al. 2017, p. 428-429) are given in section 4.

\section{THE SEVEN WORLD WONDERS OF IT}

To the question: What are the Seven Wonders of Computer Science?, Alan Kay answered: 'The things I have found astonishing and amazing (and shocking) are: 1. Turing's notation of machines that can simulate machines completely by interpreting their description ... 2... How simple ... it is to design a whole computer from just one kind of logical element ... 3. Lisp ... 4. Sketchpad ... 5... how to have imperfect things organized in systems ... 6. ... symbolic computing ... 7. The Internet ...' (Kay 2016).

We propose the following list for the seven World world wonders of computer science:

(1) Computer Mouse - Pointing to and Controlling Objects

A computer mouse is a hand-held pointing device, today with a short-range radio communication to the connected system. The first public demonstration of a mouse controlling a computer system was given in 1968 . The first computer designed for individual use was the Xerox Alto in 1973, equipped with a mouse. Hand movements are replicated by a pointer and clicking allows to select files, programs, or actions.

\section{(2) Database - Storing and Retrieving Information}

A database management system is software for describing, storing, and querying data application-independently. Database systems contain a storage and a management component. The storage component includes all data stored in structured or non-structured form. The management component offers a query and data manipulation language for evaluating and editing data and information.

(3) Cryptography - Protecting User's Privacy

The purpose of cryptography is to protect data against access by unauthorized persons. In asymmetric cryptography, the original of a document is encoded with the recipient's public key; the recipient then decodes the document with his private key. The key pairs can also be used to authenticate the sender by generating digital signatures.

(4) Graph Grammar - Performing Concepts and Relationships

Graph grammars are formal systems for creating and replacing graphs. Graphs consist of nodes (concepts) and edges (relationships between concepts). Replacement or production rules are elements of the grammar to replace input graphs by output graphs. Graph grammars are used in software engineering, pattern recognition, computer and transport networks, for robot applications, or in logistics.

(5) Internet Browser - Searching Hypertext Worldwide

An Internet browser is a software program used to browse and display web pages from the World Wide Web. Multimedia websites are linked to each other. The user can consult all relevant documents and information for a specific search. With extensions such as semantic search engines, all contents of importance are compiled. 
(6) Blockchain - Enabling a Distributed Ledger without Central Control

A blockchain is a database for distributed accounting (ledger), including a distributed transaction management, based on peer-to-peer networks, and a consensus algorithm. Any valid block of the block chain refers to its validated blocks in front of him, creating a chain of verified blocks. Since there exists a complete copy of the blockchain on all devices of the participants, a consensus by the majority can be found.

(7) Computing by Intuition - Judging Truth to a Certain Degree

The logic based on fuzzy sets or intuitionistic fuzzy sets extends the classical logic with the two truth values true and false, since many truth values (grayscales) are allowed. This infinite set of truth values leads to thinking in degrees of truth and improves decision making. In addition, differentiated analyses can be carried out even in incomplete or vague situations, and options for action can be developed.

Now we will have a closer look to world wonder sevenworld by giving three examples.

\section{THREE SHORT CASE STUDIES}

\subsection{Applying Fuzzy Portfolio Techniques}

To illustrate the potential of soft computing and fuzzy logic, we discuss a fuzzy customer portfolio (Meier and Werro 2007, Werro 2015). For reasons of simplicity and comprehensibility, we only use two features to calculate the customer value, namely turnover in Euro (quantitative attribute) and loyalty (qualitative feature). Of course, the illustrative example can be expanded at any time by inserting quantitative and qualitative key performance indicators in a multidimensional data cube (see PhD thesis of Daniel Fasel about Fuzzy Data Warehousing 2014).

The two attributes revenue and loyalty are to be defined as follows for further discussion with two equivalence classes each:

- Turnover: The value range for the turnover should be from 0 Euro to 1'000 Euro. In addition, the two equivalence classes are defined for low sales from 0 Euro to 499 Euro, and for high sales from 500 Euro to 1'000 Euro.

- Loyalty: Customer loyalty is characterized by a qualitative attribute with values top, good, weak, and bad. Equivalence classes should be top or good for positive loyalty, and weak or bad for negative loyalty.

The customer portfolio with the selected evaluation criteria results in the four equivalence classes $\mathrm{C}_{1}, \mathrm{C}_{2}$, $\mathrm{C}_{3}$, and $\mathrm{C}_{4}$. The meaning of the classes in terms of content is expressed by semantic class names. For example, the term 'Don't Invest' is chosen for class $\mathrm{C}_{4}$ for customers with small turnover and negative loyalty. The top class $\mathrm{C}_{1}$ is given the name 'Commit Customer'. Accordingly, class $\mathrm{C}_{2}$ bears the name 'Improve Loyalty', since the customers generate a big turnover here, but are negative in the loyalty relationship. Finally, class $\mathrm{C}_{3}$ defines the customers with low sales and positive loyalty with 'Augment Turnover'.

According to Figure 2, the following conflict situations can occur with sharp customer segmentation: Customer Becker has little incentive to increase its conversion or to improve customer connection and faithfulness. $\mathrm{He}$ is in premium class $\mathrm{C}_{1}$ and enjoys the corresponding privileges. Customer Becker can be surprised if his turnover decreases a little or his loyalty bonus decreases. Suddenly, he sees himself assigned to another customer segment; in extreme cases, he falls from premium class $\mathrm{C}_{1}$ to loser class $\mathrm{C}_{4}$.

Customer Huber has a decent turnover and medium customer loyalty, but is treated as a loser. It will come as no surprise when Huber looks around the market and jumps off.

Sharp customer segmentation also creates a critical situation for Schweizer. He is currently the most profitable customer with an excellent reputation, but is unfortunately not perceived and treated by the company according to his customer value.

The conflict situations shown here as examples can be mitigated or eliminated if fuzzy customer classes are formed. For example, Becker's loyalty of the corresponding fuzzy set is positive 0.66 and negative 0.33. Becker's degree of loyalty is therefore not exclusively positive or negative as with sharp classes. The membership functions positive and negative cause that the value range of fidelity is not sharply partitioned. 
Similarly, the value range of turnover is divided into big and small by the two membership functions. This results in four classes $\mathrm{C}_{1}, \mathrm{C}_{2}, \mathrm{C}_{3}$ and $\mathrm{C}_{4}$ with continuous transitions.

The customer value is calculated by aggregating all value shares along the axes of a possibly multidimensional cube and, if necessary, normalizing them. Let's take customer Becker from Figure 2 as an example: his share of the big turnover as well as his share of the positive loyalty is calculated and standardized with a specific aggregation function of the fuzzy $\operatorname{logic}^{1}$. This results in an aggregated affiliation value of Becker to premium class $C_{1}$. The aggregated membership values of Becker to the other classes $C_{2}, C_{3}$, and $C_{4}$ can be calculated accordingly.

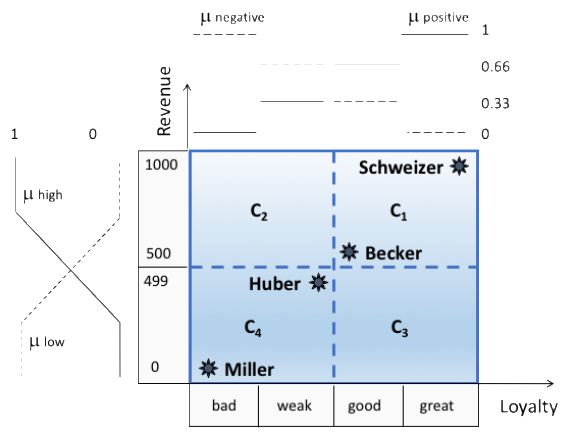

Figure 2. Fuzzy customer portfolio with individualized customer values (based on Werro 2015)

The potential benefits of using fuzzy methods in portfolio management is obious: Customers with development potential are identified at an early stage. With sharp classification boundaries, customers with potential are hardly noticeable, since all customers per class receive the same rating. With the help of quantity assignment values, however, not only customers with potential, but also customers at risk are identified at an early stage.

Marketing campaigns are expensive. With the help of small test groups it can be checked whether an expansion is worthwhile or not. If the customers addressed move in the desired direction and the increase in customer capital of this test group corresponds to the objective, the campaign can be expanded (cf. Inductive Fuzzy Classification in Kaufmann 2014 or Kaufmann et al. 2015).

Fuzzy customer or product classifications make it easier to do justice to the individualization of the electronic mass market (mass customization, see Meier and Donzé 2012). Since each customer in the multi-dimensional classification space has an individual aggregated customer value, differentiations can be made in customer relationship management. At the same time, it is possible to extract classes or subclasses of customers with similar purchasing behavior or product preferences in order to conduct targeted marketing campaigns ${ }^{2}$.

\subsection{Intuition-Based Service Management}

The core element of service level engineering is the impact analysis for the business processes of the organization. Directed graphs are used to model technical as well as software components on which the respective business process depends. In order to estimate the reliability of a business process, the components required for the process and the dependencies between the components must be evaluated. The impact analysis thus forms the basis for risk management of the computer-aided infrastructure and the application landscape. By using intuition-based fuzzy logic, an application example for the impact analysis of a business process is shown here.

\footnotetext{
${ }^{1}$ In our research center Fuzzy Management Methods at the University of Fribourg/Switzerland (www.FMsquare.org), we use in most cases the $\gamma$-operator as an aggregator, which corresponds to a compensatory AND. This operator was empirically tested as meaningful: it calculates a balanced average between the different evaluation axes, whereby the balance can be set between 0 and 1 with the $\gamma$-value. ${ }^{2}$ Michael Kaufmann tested his Inductive Fuzzy Classification approach with a real-world online marketing campaign for Postfinance, Switzerland. After this marketing campaign, the product selling rates were measured during three months. The sales rate with fuzzy classification was $0.63 \%$, crisp classification reached $0.30 \%$, and random selection resulted in $0.20 \%$ (Kaufmann 2014, p. 58)
} 
In Figure 3, we illustrate a small section of a graph model for the impact analysis of a concrete business process $G_{7}$, which is dependent on five components $K_{1}$ to $K_{5}$. A graph model for impact analysis therefore consists of two types of nodes: Business processes $\mathrm{G}_{\mathrm{i}}$, and components $\mathrm{K}_{\mathrm{j}}$. The directed edges are relationships between the components, or between components and business processes, and are modelled with the help of Intuitionistic Fuzzy Sets (Atanassov 2012). In other words, the directed edges annotated with intuitionistic fuzzy sets express the impact between the start node and the end node, including the degree of uncertainty.

In the dependency graph of Figure 3 , for example, the business process $\mathrm{G}_{7}$ is dependent on the component $\mathrm{K}_{1}$ with the following values $(0.2,0.5,0.3)$; the dependency of the business process $\mathrm{G}_{7}$ on its component $\mathrm{K}_{1}$ is expressed with the membership function $\mu\left(\mathrm{K}_{1}, \mathrm{G}_{7}\right)=0.2$. Similarly, the degree of non-dependence is determined with the non-membership function $v\left(\mathrm{~K}_{1}, \mathrm{G}_{7}\right)=0.5$. Accordingly, the degree of uncertainty can be calculated: $1-\mu\left(K_{1}, G_{7}\right)-v\left(K_{1}, G_{7}\right)=1-0.2-0.5=0.3$. Thus, we obtain the triple for the dependency $K_{1} \rightarrow G_{7}$ as $(0.2,0.5,0.3)$.

The direct dependencies in the impact graph are annotated on the basis of experience or surveys. These are given for all edges in the example in Figure 3. However, all indirect dependencies (e.g., the dependency of the business process $\mathrm{G}_{7}$ on the component $\mathrm{K}_{4}$ for a possible failure A in figure 3 ) must also be calculated. Finally, we want to know on which components and to what degree the business process $\mathrm{G}_{7}$ to be considered is dependent.

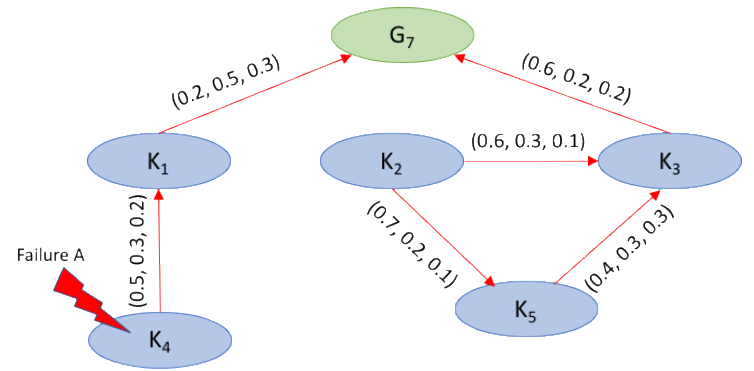

Figure 3. Graph model for the impact analysis of the business process $G_{7}$ (based on Schütze 2016)

In their research paper (Kolev and Ivanov 2009, p. 12), Boyan Kolev and Ivaylo Ivanov proposed the two formulas for a moderate impact analysis for the logical linkage of relationship edges $E_{i}$ and $E_{j}$ (for $E_{i}$ and $E_{j}$, only the values of the membership degrees $\mu$ and non-membership degrees $v$ are taken into account, since the uncertainty results from these two parts):

$$
\begin{aligned}
& E_{\mathrm{i}} \text { AND } E_{\mathrm{j}}=\left(\mu\left(\mathrm{E}_{\mathrm{i}}\right) * \mu\left(\mathrm{E}_{\mathrm{j}}\right), v\left(\mathrm{E}_{\mathrm{i}}\right)+v\left(\mathrm{E}_{\mathrm{j}}\right)-\left(v\left(\mathrm{E}_{\mathrm{i}}\right) * v\left(\mathrm{E}_{\mathrm{j}}\right)\right)\right) \\
& \mathrm{E}_{\mathrm{i}} \text { OR } \mathrm{E}_{\mathrm{j}}=\left(\mu\left(\mathrm{E}_{\mathrm{i}}\right)+\mu\left(\mathrm{E}_{\mathrm{j}}\right)-\left(\mu\left(\mathrm{E}_{\mathrm{i}}\right) * \mu\left(\mathrm{E}_{\mathrm{j}}\right)\right), v\left(\mathrm{E}_{\mathrm{i}}\right) * v\left(\mathrm{E}_{\mathrm{j}}\right)\right)
\end{aligned}
$$

These two formulas were successfully tested for service level engineering in Roland Schütze's doctoral thesis in various case studies (Schütze 2016, Schütze and Fromm 2018); among others, for an e-health service provider in Switzerland (Balkenende et al. 2017).

The aim of any impact analysis is to assess the reliability of business processes. The easiest way to do this is to identify the direct and indirect process dependencies for all components. In our use case from Figure 3, these would be the following dependencies: direct dependency from $K_{1}$ to $G_{7}=(0.2,0.5,0.3)$, direct dependency from $\mathrm{K}_{3}$ to $\mathrm{G}_{7}=(0.6,0.2,0.2)$, indirect dependency from $\mathrm{K}_{4}$ to $\mathrm{G}_{7}=(0.1,0.65,0.25)$, indirect dependency from $K_{2}$ to $G_{7}=(0.4272,0.3056,0.2672)$, and, finally, indirect dependency from $K_{5}$ to $G_{7}=(0.24,0.44,0.32)$.

Every organization that is dependent on functional information systems tries to find a balance between risk and cost. With the help of intuition-based evaluated impact graphs, the failure of business processes (or the violation of service level agreements) can be studied and risks can be weighed by storing the risks, for example with monetary values. The following questions arise for the management: What are critical technical and critical software components of a core process, measured by the respective dependency and/or independency of these components or by the degree of uncertainty? What does the failure of a core process costs for a duration of 5,10 or 30 minutes or even hours? Which investments are worthwhile for redundant components or fault-tolerant software solutions? With impact analysis and a monitoring of ongoing operations, risk management allows targeted investments to be made in order to optimize the benefits for the organization. 


\subsection{Overcoming Political Crisis by Fuzzy Voting}

Democracy is a political system in which power and legitimacy of a government emanate from the people. Political decisions are made in votes and elections. In direct-democratic democracies, the people make their own decisions on matters of fact, while in representative democracies the citizens elect representatives who exercise power.

Political crises often manifest themselves when tight decisions are made in political elections or votes. After such decisions, the people are divided into two camps: Winners and losers. This is the case with all political decisions, but with tight decisions it is up to few votes who is the winner and who is the loser.

Let's look at an example: In the Brexit vote of 2016, the citizens of Great Britain voted whether their country should remain in the European Union or not. The turnout was $72.2 \%$. The UK's withdrawal from the EU was supported by $51.9 \%$ of voters, i.e., approximately 17.4 million or $37.4 \%$ of eligible voters. $48.1 \%$ voted to remain in the EU. The results in the respective regions are also interesting: Among the Brexit supporters, England voted $53.3 \%$ for resignation, and $46.7 \%$ for remaining, while Wales voted $52.5 \%$ for resignation, and $47.5 \%$ for remaining. Among the EU proponents, Northern Ireland voted $44.2 \%$ for Brexit, and $55.8 \%$ against, while Scotland voted $38 \%$ for Brexit, and $62 \%$ against.

What do this example tell us? In political elections or votes, it is often the case that the election of political representatives is extremely close or that the proponents and opponents of a political program are in balance. In these cases, there is a rift through the population and confidence in democratic processes can suffer.

What could be done better? Tight decisions lead to a polarizing society that divides itself into opposing camps with opposing views. In our view, the causes of such a development lie in the democratic electoral system itself, since it is based on dichotomy. There is only one Yes or No, one for or one against, one right or one wrong. A complex world full of differentiations is pressed into black and white images. What for?

In our opinion, fuzzy logic is closer to human thought, speech, behavior and action than classical logic, which only distinguishes between right and wrong. Researcher Paulo Corte-Real expressed this conflict in 2007 in a scientific paper entitled 'Fuzzy voters, crisp votes'. By this he means that people with differentiated assessments are doomed to crisp or sharp voting. He calls the respective voting systems 'binary choice voting' systems and pleads for fuzzy voting (Corte-Real 2007).

A fictitious and simple example of this is given in Figure 4. A total of 21 citizens vote on a political project. In the first case of crisp votes we count 11 votes for Black and 10 votes for White; the project is rejected by $52.4 \%$. In the second case of a fuzzy vote, 4 citizens are for Black, 7 for White and 6 for fifty-fifty, i.e., half for and half against it, and finally, 4 are in favor of White to $75 \%$ ( 0.75 for White and 0.25 for Black). As a final result, we receive an approval of $61.9 \%$ for White.

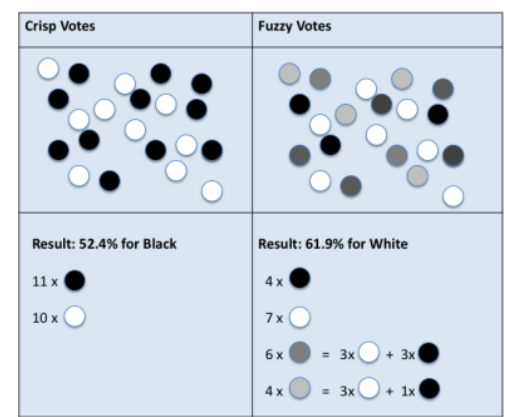

Figure 4. Differences between sharp and fuzzy voting behavior, based on Ladner and Meier 2014

Why does the mood shift from rejection (crisp black votes $52.4 \%$ ) to approval (fuzzy voting with a total of white votes $61.9 \%)$ ? One possible explanation lies in the fact that many citizens are basically in favor of a project ('something should be improved'), albeit with reservations. As a result, the majority of voters who want to avoid black-and-white clichés are in favor of acceptance, although they would like to make improvements. If the above vote is a consultative vote, a number of shortcomings could be remedied if the comments of supporters (100\% for White), opponents (100\% for Black) and grey tone voters (partly for it, partly against it) were evaluated. Shouldn't we take care of our democracy and, for example, allow voting with shades of grey or other alternatives and gain experience? 


\section{LESSONS LEARNED AND OUTLOOK}

Based on the above three case studies and a series of PhD research work (see International Book Series in Fuzzy Management Methods, Springer 2019) performed at our research center at the University of Fribourg, we are convinced to combine fuzzy logic with managerial or public applications for the following reasons:

- For fuzzy evaluations and analyses, marketing specialists can apply their usual terms (e.g., linguistic variable turnover with linguistic terms big and small). Advanced classification queries such as 'Extract all customers with big turnover and positive loyalty' are intuitive and easy to perform.

- The inclusion of vague or incomplete facts in the decision making process is possible. For example, fuzzy methods allow to model and include qualitative or subjective assessments of customer relationships. The consideration of soft indicators therefore makes it possible to differentiate and improve decision-making processes.

- For the analysis of markets, fuzzy logic allows demographic, geographic, behavioral and psychographic market segmentations. It is more realistic and successful to target markets fuzzily and to position brands or companies by applying fuzzy methods.

- It is not only in banking or insurance that individuals of companies have to be divided into risk classes. With a fuzzy logic approach, the calculation of risk degrees, creditworthiness or other indicators can be carried out with finer granularity.

- The equal treating of quantitative and qualitative attributes makes the fuzzy logic approach attractive for web analytics, web controlling, and social media monitoring.

For a long time the view was held that the two halves of the brain are responsible for different human abilities (see Figure 5): the left half of the brain is responsible for language, logic, arithmetic, analysis or laws and thus for thinking. The right hemisphere, on the other hand, controls intuition, creativity, symbolism and activates associations for images, sounds or feelings. Of course, the two brain hemispheres cannot be viewed in isolation, but should rather be interpreted in the sense of both according to more recent neuroscientific studies. For our discussion, however, this idealized representation of the hemispheres of the brain is intended to stimulate the idea that both ability spectra, those of thinking and intuition, should be taken into account when creating and using information systems. This is the only way to analyze and interpret complex data of our real life with a computer.

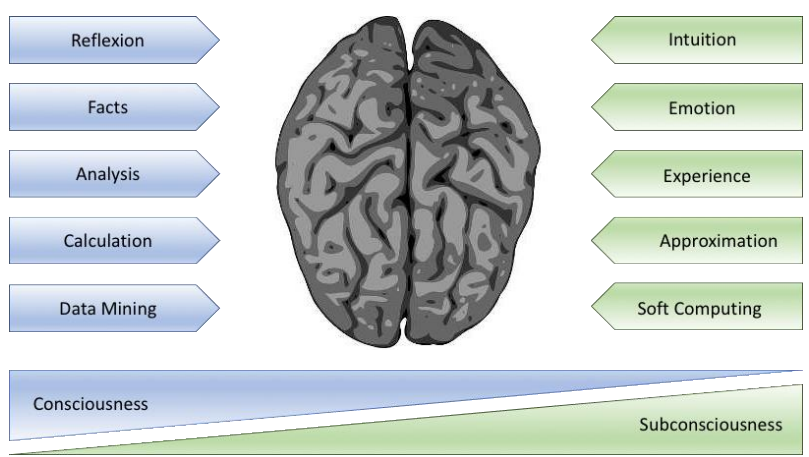

Figure 5. Idealized representation of the two brain hemispheres adopted from Meier and Portmann 2019

According to Figure 5, the potential of computer technology can be increased by applying fact-based and analytical methods (data mining) as well as soft computing methods. Soft computing provides a toolbox for modeling and processing inaccuracy, uncertainty and partial truth. Belohlavek et al. (2017) have given a historical perspective about fuzzy logic and mathematics and conclude on page 428-429: "The challenge ... is the rejection of one principle upon which logic has been based for millennia - the principle of bivalence. ... the paradigm shifts in [fuzzy] logic and mathematics ... induce possible paradigm shifts in all areas of human affairs ... This includes not only the various areas of science, but also other areas, such as engineering, medicine, management, business, decision-making, risk analysis, and many others ... It is clearly a paradigm shift on a very large scale, which may justifiably be called a grand paradigm shift.' 
In contrast to classical logic, which is based on conscious intelligence, fuzzy logic or intuitionistic fuzzy logic could help to carry out problem analysis in a more differentiated way and to approach solutions that are not exclusively based on hard facts. In short, intuition is unconscious intelligence and can enrich both big data analytics and traditional business intelligence.

\section{ACKNOWLEDGEMENT}

The author of this paper is thankful to his PhD students who did most of the research mentioned here: Alex Denzler, Daniel Fasel, Michael Kaufmann, Aigul Kaskina, Edy Portmann, Roland Schütze, Henrik Stormer, Luis Teran, Nicolas Werro, and Darius Zumstein. This paper is dedicated to the members of the international foundation FMsquare.org to motivate them in diffusing knowledge about fuzzy management methods not only to the research community but also to practice and society.

\section{REFERENCES}

Atanassov, K., 2012: On Intuitionistic Fuzzy Sets Theory. Studies in Fuzziness and Soft Computing, Springer, Heidelberg. Atanassov, K., 2016: Intuitionistic Fuzzy Logics. Studies in Fuzziness and Soft Computing, Springer, Heidelberg.

Balkenede, D., Schütze, R., Meier, A., 2017: An Intuitionistic Fuzzy Service Modell - Use Case for Swiss Platform. In: Meier, A., Portmann, E., Stoffel, K., Teran, L. (eds.): The Application of Fuzzy Logic for Managerial Decision Making Processes - Latest Research and Case Studies. Springer, Heidelberg, pp. 47-58.

Belohlavek, R., Dauben, J. W., Klir, G. J., 2017: Fuzzy Logic and Mathematics - A Historical Perspective. Oxford University Press, New York, USA.

Corte-Real, P., 2007: Fuzzy voters, crisp votes. International Game Theory Review, Vol. 09, Issue 01, pp. 67-86.

Fasel, D., 2014: A Fuzzy Data Warehousing for Performance Measurement - Concept and Implementation. Springer, Heidelberg.

Kaufmann, M., 2014: Inductive Fuzzy Classification in Marketing Analytics. Springer, Heidelberg.

Kaufmann, M., Meier, A., Stoffel, K., 2015: IFC-Filter: Membership function generation for inductive fuzzy classification. Expert Systems with Applications, 21(42), pp. 8369-8379.

Kay, A., 2016: What are the Seven Wonders of computer science? Quora, available under https://www.quora.com/ What-are-the-Seven-Wonders-of-computer-science; retrieved November 9, 2019.

Kolev, B., Ivanov, I., 2009: Fault Tree Analysis in an Intuitionistic Fuzzy Configuration Management Database. 13th International Conference on Intuitionistic Fuzzy Sets, Sofia, Bulgaria, May 9-10, NIFS Vol. 15, pp. 10-17.

Ladner, A., Meier, A., 2014: Digitale politische Partizipation - Spannungsfeld zwischen MyPolitics und OurPolitics. HMD Praxis der Wirtschaftsinformatik, Jahrg. 51, Heft 6, Springer, Heidelberg, S. 867-882.

Meier, A., Donzé, L. (eds.), 2012: Fuzzy Methods for Customer Relationship Management and Marketing - Applications and Classifications. IGI Global, Hershey PA, USA.

Meier, A., Portmann, E., 2019: Fuzzy Management - Trilogie II: Einsatz der unscharfen Logik für Business Intelligence. Springer essentials, Heidelberg.

Meier, A., Werro, N., 2007: A Fuzzy Classification Model for Online Customers. Journal Informatica 31, pp. 175-182.

Schütze, R., 2016: Improving Service Level Engineering - An Intuitionistic Fuzzy Approach. Springer, Heidelberg, 2016.

Schütze, R., Fromm, H.-J., 2018: Intuitionistic Fuzzy Logic - Anwendungsoptionen im IT Service Management. In: Meier A., Seising R. (Hrsg.): Vague Information Processing. HMD Praxis der Wirtschaftsinformatik, Jahrg. 55, Heft 3, Springer, Heidelberg, S. 566-580.

Springer 2019: International Research Book Series in Fuzzy Management Methods; available under https://www.springer.com/series/11223; retrieved November 9, 2019.

Werro, N., 2015: Fuzzy Classification of Online Customers. Springer, Heidelberg.

Zadeh, L.A., 1965: Fuzzy Sets. Information and Control 8, pp. 338-353. 